\title{
Stage IIB Lung Cancer AJCC v7
}

National Cancer Institute

\section{Source}

National Cancer Institute. Stage IIB Lung Cancer A/CC V7. NCI Thesaurus. Code C5645.

Stage IIB includes: (T 2b, N1, M0); (T3, N0, M0). T2b: Lung cancer with a tumor size more than $5 \mathrm{~cm}$ but $7 \mathrm{~cm}$ or less in greatest dimension. T3: Lung cancer with a tumor size more than $7 \mathrm{~cm}$ or one that directly invades any of the following: parietal pleural (PL3) chest wall (including superior sulcus tumors), diaphragm, phrenic nerve, mediastinal pleura, parietal pericardium; or tumor in the main bronchus (less than $2 \mathrm{~cm}$ distal to the carina but without involvement of the carina); or associated atelectasis or obstructive pneumonitis of the entire lung or separate tumor nodule(s) in the same lobe. N0: No regional lymph node metastasis. N1: Lung cancer with metastasis in ipsilateral peribronchial and/or ipsilateral hilar lymph nodes and intrapulmonary lymph nodes, including involvement by direct extension. M0: No distant metastasis. (AJCC 7th ed.) 